\title{
Predominantly Venous Malformation Associated with the Median Artery of Forearm
}

\section{Abeysekera WYM ${ }^{1 *}$, Beneragama TS $^{2}$ and Athiththan $\mathbf{S P}^{1}$}

${ }^{1}$ Registrar in Plastic and Reconstructive Surgery, National Hospital, Colombo, Sri Lanka

${ }^{2}$ Consultant Plasti and Reconstructive Surgeon, National Hospital, Colombo, Sri Lanka

\begin{abstract}
Vascular malformations (VM) of the hand and forearm are rare lesions which need accurate diagnosis and optimal management. Many confusing classifications were developed to define these vascular malformations. Presence of a median artery in the forearm of an adult is a rare occurrence. In this we report a predominantly venous malformation of the distal forearm associated with the Palmar type Median artery which is an extremely rare situation and to the best of our knowledge this is the first report of such association.
\end{abstract}

\section{Introduction}

Most of the vascular lesions of the hand and forearm are either haemangiomas, true Arterio venous malformations (AVM) or predominantly venous malformations (PVM) [1,2]. Median artery is a transitory vessel that represents the arterial axis of the forearm during early embryonic life which disappears in the second embryonic month [3]. Rarely this vessel will persist till adult life. As described in many cases anatomy of a such presence would be Either a small and short vessel which ends prior to the entry of carpel tunnel (antebrachial type) or as in our case a larger longer vessel extending through carpel tunnel to the hand (Palmar type) [4].

\section{Case}

A thirty two years old male from southern province of Sri lanka has presented with a painful soft lump in the flexor aspect of the distal forearm of Right upper limb. He notices this lump about 15 years back and for many years it was asymptomatic except for extremely slow rate of growth. But he developed mild pain and tingling sensation along the median nerve distribution of the hand especially associated with movements of the wrist. On examination it was a non pulsatile lump deep to the skin which was soft and compressible. MRI of the hand described a possibility of a vascular malformation extending to the hand. Digital Substraction Angiography confimed the possibility of venous malformation or haemangoma without AVM.

On exploration the vascular malformation was extending from distal forearm through the carpel tunnel in to the hand (Figure 1). It was surrounding the median nerve and a relatively bigger vessel was accompanying the median nerve, which we identified as a median artery

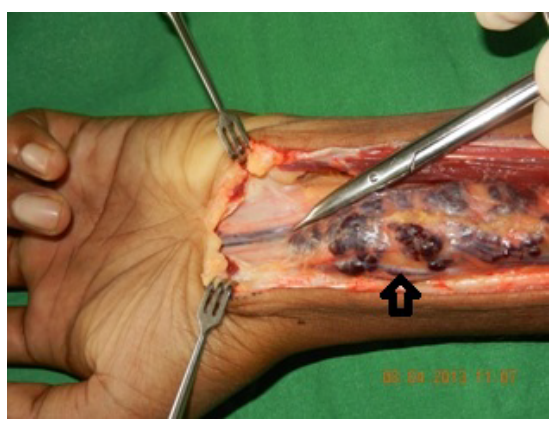

Figure 1: Black arrow indicating the VM surrounding the Median nerve and median artery in the distal forearm.

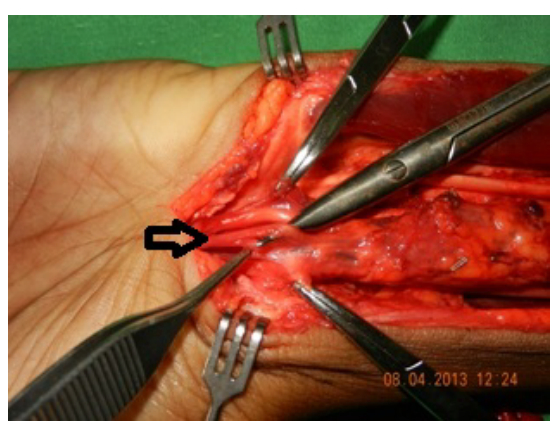

Figure 2: Black arrow indicating the median artery with median nerve underneath the incised flexor retinaculum.

(Figure 2). This was the main feeder of the malformation and there were several minor feeders arising from radial and ulnar arteries supplying the malformation from either side (Figure 3). We excised most of the malformation after ligating the median artery both proximal and distal ends, except for the segment in close proximity to the nerve due to the risk of damage to the nerve in an attempt of vigorous clearance (Figure 4). We did not dissect distally or proximally to confirm the continuity of the median artery since it was beyond the scope of our surgery. Post op recovery of the patient was uneventful.

\section{Discussion}

Role of the median artery would be to function as a nutrient vessel to the median nerve [5] and to supply surrounding muscles and structures in close proximity to the nerve [6]. Antebrachial type is the commoner type with an incidence ranging from $70-100 \%$, the palmar type is relatively rarer with the incidence of $1.5-50 \%$. Only two

*Corresponding author: Abeysekera WYM, No. 10A, Mission lane, Pita-Kotte, Kotte, Colombo, Sri Lanka, E-mail: yohan.abeysekera@yahoo.com

Received August 24, 2013; Accepted October 12, 2013; Published October 14 2013

Citation: Abeysekera WYM, Beneragama TS, Athiththan SP (2013) Predominantly Venous Malformation Associated with the Median Artery of Forearm. J Vasc Med Surg 1: 117 doi: 10.4172/2329-6925.1000117

Copyright: () 2013 Abeysekera WYM, et al. This is an open-access article distributed under the terms of the Creative Commons Attribution License, which permits unrestricted use, distribution, and reproduction in any medium, provided the original author and source are credited. 


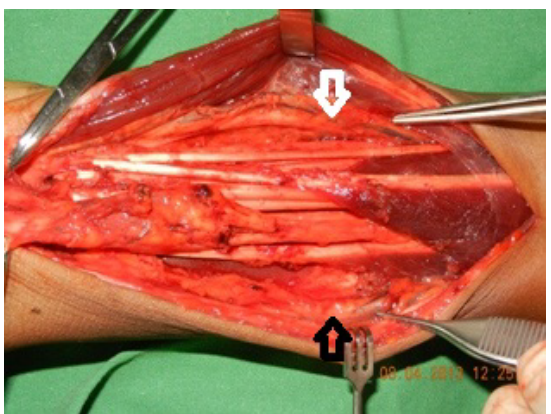

Figure 3: White arrow indicating the ulnar artery and black arrow indicating the radial artery, with flexor tendons visible in the center after excision of the VM.

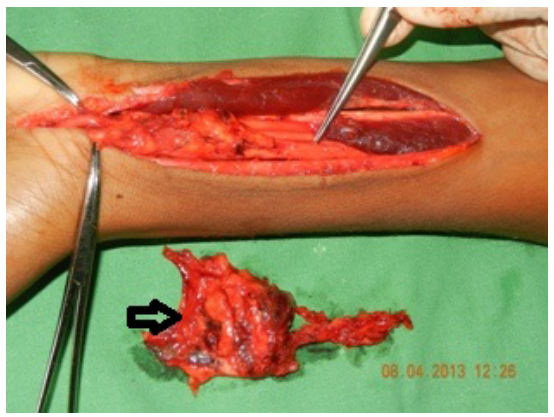

Figure 4: Black arrow indicating the removed VM.

anatomical studies have documented the presence of both subtypes in the same limb [4].

The origin of the median artery could be from the ulnar, anterior interosseous, common interosseous and radial arteries or from the caudal angle between the ulnar and common interosseous arteries. Common course of this vessel would be a path between the anterior surface of the median nerve and the deep surface of FDS, except for some cases where it has also been identified as a superficial vessel anterior to the superficial forearm flexors [4].

In Seventy four percent of cases the antebrachial pattern terminates in the upper third of the forearm within the median nerve sheath and in the distal third of the forearm within the flexor tendon sheaths or as a very thin branch in the median nerve sheath in rest of the instances, but $60 \%$ of palmar patterns of the median artery ended as the $1^{\text {st }}, 2^{\text {nd }}$ or $1^{\text {st }}$ and $2^{\text {nd }}$ common digital arteries and in rest of the cases the vessel terminated completing the superficial palmar arch [4].

The median artery in its palmar pattern which runs in the carpal tunnel together with the median nerve and flexor tendons has been considered as a risk factor in the carpal tunnel syndrome [3,7]. Also the piercing of the median nerve by the median artery in the upper third of the forearm has been described and implicated in the 'pronator teres syndrome' [8] and 'Anterior interosseous nerve syndrome' [9].

Among many growth lesions occurring in the hand and forearm, vascular malformations will take the fourth place [10]. These are mostly sporadic in origin, and rarely associated with familial syndromes. It is thought to be present from birth in otherwise healthy young individuals $[11,12]$.

According to Mulliken and Glowacki, origin of these congenital vascular malformations could be a result of abnormal development of the embryonic vascular system. Unlike haemangiomas they are not neoplasms and they do not exhibit the sequence of rapid proliferation followed by spontaneous involution $[13,14]$.

VM is treated if the patient is symptomatic only. The commonest complains of forearm and hand VM would be pain, swelling, discoloration of the skin, distal ischemic symptoms and overgrowth of the extremity and size discrepancy when compared to the normal side. Hyperhidrosis with café au lait had been seen in some cases which indicate the abnormal communication of the VM with regional neural tissues [11]. Prior to treatment an exact vascular anatomy should be clarified by arteriography and venography [15]. True AVM will be high flow lesions and PVM can be identified as typical low flow lesions.

In spite of many treatment options described over the years still the exact treatment option of VM is a mystery. As recent advances in interventional radiology has assured a better handling in VM by super selective catheterization of the feeder vessels allowing a higher control, thus surgical resection or transcatheter embolization or the combination of both would be the best treatment options at present $[16,17]$.

\section{References}

1. Upton J, Coombs CJ, Mulliken JB, Burrows PE, Pap S (1999) Vascular malformations of the upper limb: a review of 270 patients. J Hand Surg Am 24: 1019-1035.

2. Eichenfield LF (1998) Evolving knowledge of hemangiomas and vascular malformations: beyond strawberries and port wine. Arch Dermatol 134: 740742

3. Singla RK, Kaur N, Dhiraj GS (2012) Prevalence of the Persistant Median Artery. J Clin Diagn Res 6: 1454-1457.

4. Rodríguez-Niedenführ M, Sañudo JR, Vázquez T, Nearn L, Logan B, et al (1999) Median artery revisited. J Anat 195: 57-63.

5. Sunderland S (1945) Blood supply of the nerves of the upper limb in man. Archives of Neurology and Psychiatry 53: 91-115.

6. Blunt MJ (1959) The vascular anatomy of the median nerve in the forearm and hand. J Anat 93: 15-22.

7. Chalmers J (1978) Unusual cases of peripheral nerve compression. The Hand 10: $167-175$.

8. Jones NF, Ming NL (1988) Persistent median artery as a cause of pronator syndrome. J Hand Surg Am 13: 728-732.

9. Proudman TW, Menz PJ (1992) An anomaly of the median artery associated with the anterior interosseous nerve syndrome. J Hand Surg $\mathrm{Br}$ 17: 507-509.

10. McClinton MA (1993) Tumors and aneurysms of the upper extremity. Hand Clin 9: 151-169.

11. Sofocleous CT, Rosen RJ, Raskin K, Fioole B, Hofstee DJ (2001) Congenita Vascular Malformations in the Hand and Forearm. J Endovasc Ther 8: 484-494.

12. Blei F, Walter J, Orlow SJ, Marchuk DA (1998) Familial segregation of hemangiomas and vascular malformations as an autosomal dominant trait. Arch Dermatol 134: 718-722.

13. Mulliken JB, Glowacki J (1982) Hemangiomas and vascular malformations in infants and children. A classification based on endothelial characteristics. Plast Reconstr Sur 69: 412-422.

14. Folkman J (1984) Toward a new understanding of vascular proliferative disease in children. Pediatrics 74: 850-856

15. Vogelzang RL (1991) Arteriography of the hand and wrist. Hand Clin 7: 63-86.

16. Widlus DM, Murray RR, White RI Jr, Osterman FA Jr, Schreiber ER, et al. (1988) Congenital arteriovenous malformations: tailored embolotherapy. Radiology 169: 511-516.

17. Dickey KW, Pollak JS, Meier GH, Denny DF, White RI Jr (1995) Management of large high-flow arteriovenous malformations of the shoulder and uppe extremity with transcatheter embolotherapy. J Vasc Interv Radiol 6: 765-773. 